\title{
Expression of CD44 in normal and rheumatoid synovium and cultured synovial fibroblasts
}

\author{
Keiran J Henderson, Jo C W Edwards, Jennifer G Worrall
}

\begin{abstract}
Objective-To determine if expression of CD44, the principal receptor for hyaluronan, was altered in rheumatoid (RA) synovium and cultured rheumatoid synovial fibroblasts.

Methods-Synovium was obtained from normal adult human joints $(n=4)$ and from joints of patients with $R A(n=5)$. Specific monoclonal antibodies to CD44 were used in immunofluorescence of whole synovium and cultured synovial fibroblasts and in quantitative Western blotting and ELISA of CD44 in cultured synovial fibroblasts.
\end{abstract}

Results-CD44 was restricted to the lining layer in normal synovium but present, in reduced concentrations, throughout rheumatoid synovium. Cultured rheumatoid cells were $19 \%$ larger in area and showed far fewer and less extensive CD44-positive cytoplasmic extensions, together with reduced staining intensity compared with normal. Quantitative Western blotting normalised for cell protein showed a $75 \%$ reduction (normal $=1754$ (835), rheumatoid $=409$ (84) mean (SD) arbitrary units) in the amount of CD44 in rheumatoid cells compared with normal, and enzyme linked immunosorbent assay (ELISA) of cultured cell monolayers normalised for cell number indicated a $29 \%$ reduction (normal $=0.707 \quad(0 \cdot 110)$, rheumatoid $=0.504(0.103)$, mean (SD) optical density at $405 \mathrm{~nm}$ ).

Conclusions-Rheumatoid synovial cells showed altered morphology and reduced CD44 expression compared with normal cells. CD44, by means of modulated associations with the cytoskeleton, may be involved in cell shape change.

(Ann Rheum Dis 1994; 53: 729-734)

Synovial Biology Group, Department of Rheumatology Research, University College London Medical School, London, United Kingdom

$\mathrm{KJ}$ Henderson

J C W Edwards

J G Worrall

Correspondence to: Dr K Henderson,

Department of

Rheumatology Research,

UCLMS, Arthur Stanley

House, Tottenham Street,

Louse, Tottenham W1P 9PG.

Accepted for publication 21 July 1994
CD44 (extracellular matrix receptor III, pgp-1, Hermes antigen) is the principal cell surface receptor for the ubiquitous matrix glycosaminoglycan hyaluronan ${ }^{1}$ and is expressed on a wide variety of cells, including fibroblasts, macrophages, lymphocytes, epidermal cells, and smooth muscle cells. ${ }^{2}$ The amino terminus of the CD44 molecule shares sequence homology with other hyaluronan binding proteins such as cartilage link protein, ${ }^{3}$ aggrecan, ${ }^{4}$ and versican. ${ }^{5}$ The hyaluronan binding sites of CD44 have been identified. ${ }^{6}$ CD44 also binds the carboxy terminal heparin binding region of fibronectin ${ }^{7}$ and it is thought that this interaction may modulate matrix turnover. The extracellular domain of CD44 contains several serine-glycine pairs which are potential glycosaminoglycan attachment sites. ${ }^{8}$

The gene sequence of lymphocyte CD44 predicts a transmembrane protein of $37 \mathrm{kDa}^{9}$ but, as a result of post-translational glycosylation, its apparent molecular mass on sodium dodecyl sulphate polyacrylamide gel electrophoresis is around $85 \mathrm{kDa} .{ }^{10}$ Further isoforms, not all of which bind hyaluronan, are generated by alternative splicing of the CD 44 gene; $;^{11}$ this results in a number of variants of the basic molecule which include a truncated cytoplasmic domain and the insertion of a 132 amino acid sequence. ${ }^{3}{ }^{12} \mathrm{~A}$ variant of CD44 which is transiently expressed on $B$ and $T$ lymphocytes has been implicated in the metastasis of tumour cells. ${ }^{13}$ The form of CD44 on synovial fibroblasts has not yet been characterised.

In its role as a receptor for hyaluronan, CD44 is involved in the uptake and degradation of hyaluronan, although it does not appear to possess any hyaluronan degrading activity itself. ${ }^{14}$ CD44 also mediates cell migration on hyaluronan substrates, ${ }^{15}$ which is of interest as hyaluronan accumulates in areas of cell migration, ${ }^{16}$ inflammation, ${ }^{17}$ and tumour invasion. ${ }^{18}$ In rheumatoid arthritis (RA), there is evidence of increased production of hyaluronan. Synovial fluid from rheumatoid joints contains increased total quantitites of hyaluronan, although the concentration is smaller than in synovial fluid from normal joints. ${ }^{19}$ Fibroblasts cultured from RA synovium show greatly increased synthesis of hyaluronan. ${ }^{20}$

Recent studies purport to show that CD44 is increased on many synovial cell types in $\mathrm{RA}^{21}$ and that the level of CD44 present in the synovial tissue is related to the degree of synovial inflammation. ${ }^{22}$ The aims of this study were two-fold: to investigate the distribution of CD44 in normal and rheumatoid synovial tissue, and to investigate CD44 expression by fibroblasts cultured from normal and rheumatoid synovium.

\section{Materials and methods}

MONOCLONAL ANTIBODIES

Table 1 gives details of the monoclonal antibodies (MAb) used. Antibodies were used at an appropriate dilution optimised by titration for each technique. The three antibodies to CD44 used in this study recognise the hyaluronan binding form of CD44: F.10.44.2 and A3D8 bind to the same determinant, whereas F.10.62.1 binds to a separate site on the CD44 molecule. ${ }^{23}$ 
Table 1 Monoclonal antibodies (MAb) used in this study and their specificities

\begin{tabular}{lll}
\hline MAb and Ig class & Molecule detected & Source \\
\hline F.10.44.2, IgG2a & CD44 & Prof J Fabre \\
F.10.62.1, IgG1 & CD44 & Prof J Fabre \\
A3D8, IgG1 & CD44 & Sigma, UK \\
5B5, IgG1 & Prolyl hydroxylase & DAKO, UK \\
32.2, IgG1 & FcrR-1 (CD64) & Dr M Fanger \\
MPO-1, IgG1 & Myeloperoxidase & Dr G Cambridge \\
\hline
\end{tabular}

TISSUES

Normal synovium $(n=4)$ was obtained from the knee joints of patients undergoing amputation for localised proximal sarcomata. Tissue was taken from macroscopically normal sites at least $30 \mathrm{~cm}$ distal to the tumour. Diseased synovium $(n=5)$ was obtained from patients with definite or classic rheumatoid arthritis according to the criteria of the American Rheumatism Association, ${ }^{24}$ undergoing major joint surgery. Mean age of control tissue donors was 63.5 years and that of RA patients, 68 (difference not significant by Student's $t$ test at the $95 \%$ level). All tissues were processed within two hours of removal and trimmed of capsule and fat. Blocks of approximately $5 \mathrm{~mm}^{3}$ were snap frozen in a bath of isopentane (British Drug Houses, UK) and solid carbon dioxide and stored in airtight vials at $-70^{\circ} \mathrm{C}$. Sections were cut at a thickness of $7 \mu \mathrm{m}$ on a cryostat, dried under a cool fan, wrapped in tin foil and stored at $-70^{\circ} \mathrm{C}$.

\section{CELL CULTURE}

Experiments were performed with cells which were harvested before the third passage and all cultures were supplemented with antibiotics. Cells were obtained from synovial tissue by three methods.

Explant technique-This was used for both normal and rheumatoid tissue. Blocks of fresh synovium of size $1 \mathrm{~mm}^{3}$ were placed intimal side down onto the surface of T25 tissue culture flasks which had been prewetted with Dulbecco's minimal essential medium (DMEM) containing 10\% fetal calf serum (FCS) (Tissue Culture Services, UK). After 30 minutes at $37^{\circ} \mathrm{C}$ the explants were adherent and $5 \mathrm{ml}$ of DMEM containing $10 \%$ FCS was added to each flask. The flasks were then left at $37^{\circ} \mathrm{C}$ in a humidified incubator under $5 \%$ carbon dioxide until a substantial outgrowth of cells was apparent (approximately seven days). The explants were then removed with forceps and the cells detached by $2 \cdot 5 \%$ trypsin in phosphate buffered saline (PBS), replated in fresh flasks and grown to confluence before further passage.

Trypsin digestion of the synovial lining-Used for normal synovium. The synovial surface was washed with PBS before being treated with $2.5 \%$ trypsin solution for one hour at $37^{\circ} \mathrm{C}$. The synovial surface was then gently scraped and the resulting cell suspension transferred in volumes of approximately $0.1 \mathrm{ml}$ to the wells of a 96 well tissue culture plate. The cells in each well were grown to confluence before being serially cultured through intermediate sized culture plates into T25 flasks.
Collagenase digestion-This method was used for the disaggregation of RA tissue in which the distinction between the synovial surface and the deeper tissue was less clear. Synovium was chopped into small pieces and added to a solution of collagenase (Worthington Biochemical Corp., USA) at $2 \mathrm{mg} / \mathrm{ml}$ in DMEM containing $10 \% \mathrm{FCS}$. After incubation at $37^{\circ} \mathrm{C}$ for two hours, the suspension was filtered through gauze, the cells centrifuged into a pellet at $120 \mathrm{~g}$ for 10 minutes and seeded at $10^{4}$ cells $/ \mathrm{ml}$ in T25 flasks.

\section{NON-SPECIFIC ESTERASE ACTIVITY}

Non-specific esterase activity was estimated using a standard $\alpha$-naphthyl acetate technique. ${ }^{25}$

MEASUREMENT OF CELL SURFACE AREA

Cells in $2 \%$ FCS were seeded at subconfluence onto cover slips and incubated overnight at $37^{\circ} \mathrm{C}$. Cover slips were then washed in PBS before the cells were stained with $0 \cdot 1 \%$ toluidine blue (Sigma, UK) in $0.1 \mathrm{~mol} / 1$ acetate buffer, $\mathrm{pH} 6 \cdot 2$. Cells were rinsed with distilled water and air dried. Cell areas were measured using a Zeiss standard microscope fitted with a Panasonic WVBL 600 video camera connected to an Apple Macintosh IIfx computer running NIH image software.

INDIRECT IMMUNOFLUORESCENCE

For immunofluorescence studies, cells in DMEM containing $2 \%$ FCS were seeded at subconfluence onto cover slips and incubated overnight at $37^{\circ} \mathrm{C}$. Cover slips were then washed in PBS and stored at $-70^{\circ} \mathrm{C}$ until use. Tissue sections or cells cultured on cover slips were brought to room temperature, fixed in acetone (stored at $-20^{\circ} \mathrm{C}$ ) for 10 minutes and rehydrated in PBS. Non-specific binding was blocked by incubation of samples with $10 \%$ normal goat serum (Sigma, UK) in PBS for 20 minutes at room temperature; all subsequent incubations were for 30 minutes at room temperature. Excess serum was drained off and serial samples were then incubated with primary antibody. Samples incubated with MPO-1 (an irrelevant MAb of the same class) or with PBS, in place of the specific primary $\mathrm{MAb}$, served as controls. After this and all subsequent steps, samples were washed in PBS three times to a total of 30 minutes. Samples were then incubated with fluoresceinisothiocyanate-conjugated goat antibody to mouse IgG (Sera-Lab, UK) in PBS with $10 \%$ normal human serum. Samples were mounted in the anti-fade mountant DABCO (Sigma, UK) and viewed with a Nikon research microscope with fluorescence attachment.

QUANTITATIVE WESTERN BLOT ANALYSIS Cell monolayers were detached from culture plates by incubation with $16 \mathrm{mmol} / \mathrm{EDTA}$ in PBS for 20 minutes at $37^{\circ} \mathrm{C}$ and centrifuged for 10 minutes at $1000 \mathrm{~g}$. The cell pellet was solubilised in Triton buffer $(300 \mathrm{mmol} / \mathrm{l} \mathrm{NaCl}$, 
$50 \mathrm{mmol} / 1$ Tris $\mathrm{HCl} \mathrm{pH} 7 \cdot 6,0 \cdot 5 \%$ Triton $\mathrm{X}-100,2 \mathrm{mmol} / \mathrm{l}$ phenyl methylsulphonyl fluoride) for 45 minutes on ice and the lysate centrifuged to remove cell nuclei. Ten percent sodium deoxycholate and $10 \%$ sodium dodecyl sulphate were added to the supernant to a final concentration of $0 \cdot 2 \%$. Protein content was estimated by bicinchoninic acid (BCA) assay (Pierce, UK), and samples of supernatant of equal protein content were electrophoresed on a $7.5 \%$ polyacrylamide gel under non-reducing conditions. Proteins were transferred to nitrocellulose membranes and duplicate blots were stained for CD44 using MAbs F.10.44.2, F.10.62.1, and A3D8. The secondary antibody was an alkaline-phosphatase-labelled goat antimouse Ig (Southern Biotechnology, USA). Binding was visualised with the colour development substrates 5-bromo-4-chloro-3 indolyl phosphate and nitroblue tetrazolium (Sigma, UK). Intensity of staining of the CD44 bands was measured by densitometry. Blots were scanned using a Hewlett Packard Scanjet 2C scanner connected to an Apple Macintosh IIfx running NIH Image software with a gel plotting macro.

\section{CELL BASED ELISA}

Cellular CD44 expression was measured using a cell monolayer ELISA based on the method of Chin et al. ${ }^{26}$ Cells were seeded in DMEM containing $2 \% \mathrm{FCS}$ at a density of $3 \times 10^{3}$ cells/ well in 96 well tissue culture plates and allowed to adhere before being incubated overnight with $0.5 \%, 2 \%$, or $10 \%$ FCS. The medium was removed and the cell layers washed twice with Tris buffered saline (TBS), $\mathrm{pH} 7 \cdot 6$, before fixation in $2 \%$ formaldehyde in TBS for five minutes. After a further wash in TBS, the cells were incubated with binding buffer $(0 \cdot 1 \%$ bovine serum albumin in TBS) for 60 minutes at $37^{\circ} \mathrm{C}$. The binding buffer was replaced by the primary antibody in binding buffer and incubated for 45 minutes at $37^{\circ} \mathrm{C}$. Cells were washed twice with TBS and incubated with binding buffer for 60 minutes at $37^{\circ} \mathrm{C}$. The binding buffer was then replaced with alkalinephosphatase-conjugated goat anti-mouse IgG (Southern Biotechnology, USA) at $0.2 \mu \mathrm{g} / \mathrm{ml}$ in binding buffer and the cells incubated for 45 minutes at $37^{\circ} \mathrm{C}$. After washing in TBS, cells were incubated with Sigma 104 phosphatase substrate (Sigma, UK) dissolved in bicarbonate buffer $\left(7.5 \mathrm{mmol} / / \mathrm{Na}_{2} \mathrm{CO}_{3}, 18 \mathrm{mmol} / \mathrm{l}\right.$ $\mathrm{NaHCO}_{3}$, pH 9.6) for 60 minutes. The reaction was terminated by the addition of 25 $\mu l$ of $12.5 \mathrm{~mol} / \mathrm{l}$ sodium hydroxide. One hundred microlitre aliquots of the supernatant were transferred to 96 well microtitre plates and the absorbance at $405 \mathrm{~nm}$ determined using a Dynatech MR4000 ELISA plate reader. Standard curves were established for each cell line and all assays were performed within the linear region of each standard curve.

STATISTICAL METHODS

Measurements of cell surface area were performed on samples of 40 cells per cell line,
ELISAs were performed in septuplicate and results processed using Student's two tail $t$ test. Western blot results were expressed as means of values from the two groups (normal and RA) and the difference between them tested by Student's two tail $t$ test.

\section{Results}

The findings were consistent between different specimens within the normal and rheumatoid groups and did not appear to show significant variation with patient characteristics such as age, sex, disease duration, and antirheumatic drug therapy.

\section{CULTURED CELLS}

Cells obtained by explant and enzyme digestion from the same tissue source exhibited no differences in appearance, growth rate or CD44 expression. Cells cultured from synovial tissue had the general appearance of fibroblasts, but it is known that enzymatic digestion of synovial tissue releases large numbers of macrophages as well as fibroblasts, although the macrophages seem not to survive beyond the first passage. In the absence of a specific fibroblast marker, determination of the fibroblastic nature of the cells was aided by positive staining for prolyl hydroxylase, absence of esterase activity and absence of high affinity Fc $\gamma$ receptors (data not shown).

Cultured RA synovial fibroblasts were larger (mean $=2226$ arbitrary units of area) than normal cells (mean $=1866$ arbitrary units of area). This difference was found to be statistically significant $(p<0.005)$.

\section{IMMUNOFLUORESCENCE}

In normal synovium, the bodies of the lining cells and sparsely scattered subsynovial cells were densely stained for CD44 (fig 1A). The intervening matrix showed many densely stained fibres which appeared to be cellular processes. These were closely packed in the lining layer but more widely separated in the deeper layers where the cells were scattered. The overall appearance was of dense staining throughout the lining layer, with minimal staining of the subsynovium. Rheumatoid synovium (fig 1B), in contrast, showed staining of almost all cells, including lymphocytes and vascular smooth muscle cells, throughout the depth of the tissue. The staining of the lining layer was markedly less dense than that seen in normal synovium. In both normal and diseased tissue, endothelial cells were uniformly unstained.

The findings in cultured synovial fibroblasts were consistent with but less marked than those in whole tissue. Normal fibroblasts (fig 2A) were uniformly stained and showed numerous multiply branched CD44-positive cytoplasmic processes which appeared to connect with similar processes from neighbouring cells. Rheumatoid fibroblasts (fig 2B) were less intensely stained for CD44 and showed far fewer processes and cellular interconnections. 

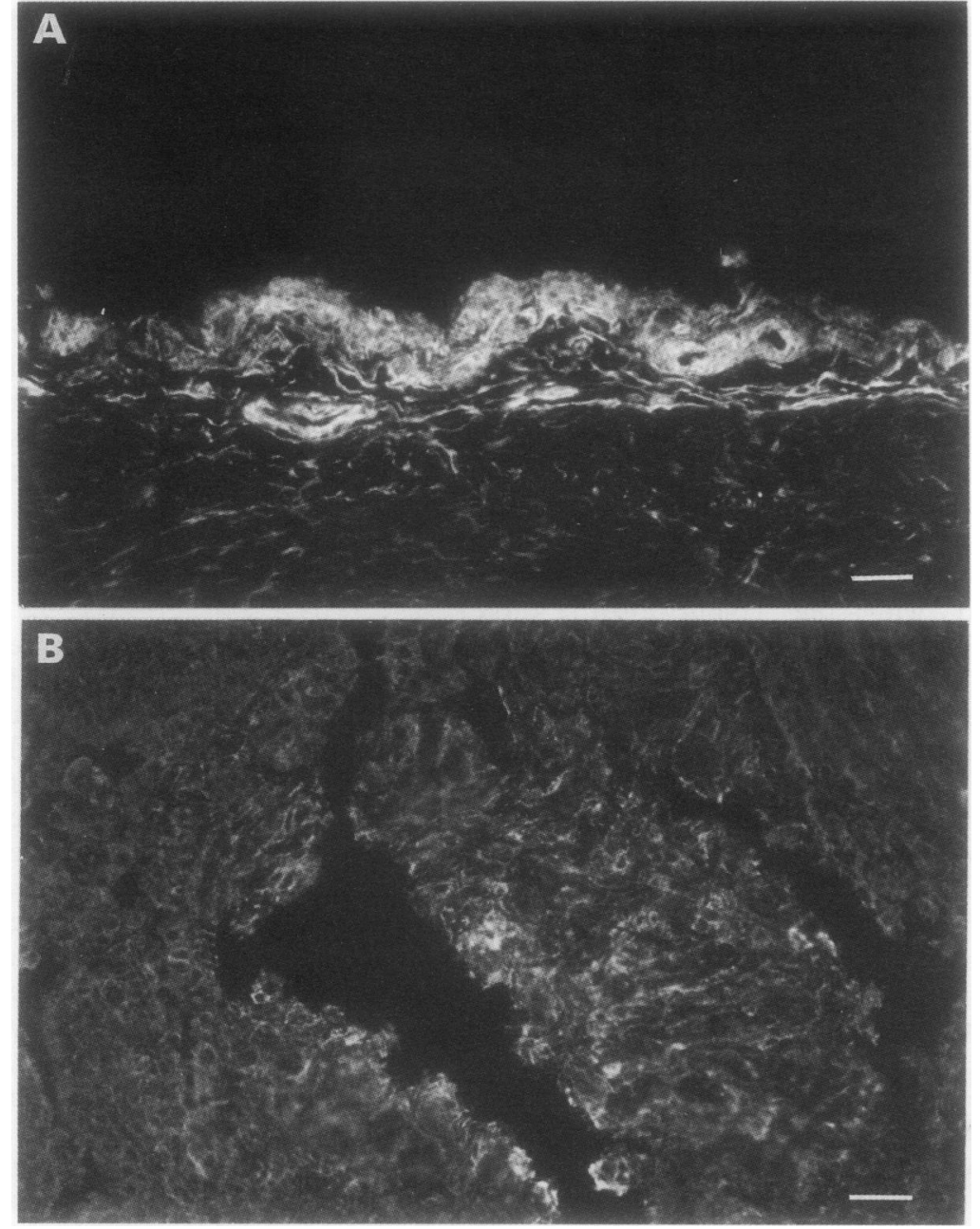

Figure 1 CD44 staining of normal $(A)$ and $R A$ (B) synovium. Although more widespread in $R A$ synovium, staining is of greatly reduced intensity compared with normal. Bar $=50 \mu \mathrm{m}$
Results shown are for MAb F.10.44.2, but similar results were obtained with each of the antibodies to CD44. Cell lysate preparations were normalised for total cellular protein, so it would appear that RA fibroblasts contain less CD44 than normal for an equivalent mass of cell protein.

CELL-BASED ELISA

There was no significant difference in optical density values obtained with normal and RA cells when they had been incubated with $2 \%$ and $10 \%$ FCS. However, at the (more physiological) concentration of $0.5 \%$, a difference of $29 \%$ was observed $(p<0.001)$ (table 2).

Results shown are for MAb F.10.44.2, but similar results were obtained with each of the antibodies to CD44.

\section{Discussion}

This study has shown by a number of methods that CD44 is expressed by synovial fibroblasts and that its expression may be reduced in rheumatoid cells.

In normal synovium, CD44 was present predominantly in the lining layer, an area known to be largely populated by fibroblasts, ${ }^{27}$ where its presence on prolonged cytoplasmic processes which minutely subdivide the matrix may help in anchorage and matrix turnover. In contrast, CD44 was present on the majority of cells, albeit expressed to a lesser extent, throughout the depth of rheumatoid synovium.

Morphological studies show hyaluronan to be distributed predominantly to the lining layer in normal synovium but to be present uniformly throughout the depth of rheumatoid tissue, ${ }^{28}$ and this study shows that synovial distribution of the hyaluronan receptor, CD44, mirrors that of hyaluronan. The finding that CD44 and its principal ligand, hyaluronan, are localised primarily to the intima in normal synovium and that no such restricted distribution is present in rheumatoid tissue adds to a number of previously identified features of the normal synovial lining which are altered in rheumatoid arthritis. These include activity of the enzyme uridine diphosphoglucose dehydrogenase (important in the synthesis of hyaluronan precursors) ${ }^{29}$ and expression of chondroitin-6-sulphate, ${ }^{30}$ vascular cell adhesion molecule- $1,{ }^{31}$ and type VI collagen. ${ }^{32}$

A recent study by Johnson et $a l^{21}$ found that, for a number of cell types, the percentage of CD44-positive cells was increased in RA synovium compared with normal and it was concluded that CD44 is upregulated in RA. However, individual cell types were identified on serial sections rather than by double labelling and no attempt was made to quantify the level of expression of CD44. Certainly, in RA synovium there is a massive influx of cells (largely macrophages and lymphocytes) which constitutively express CD44, but we have found no evidence for upregulation of CD44 on individual cells. 

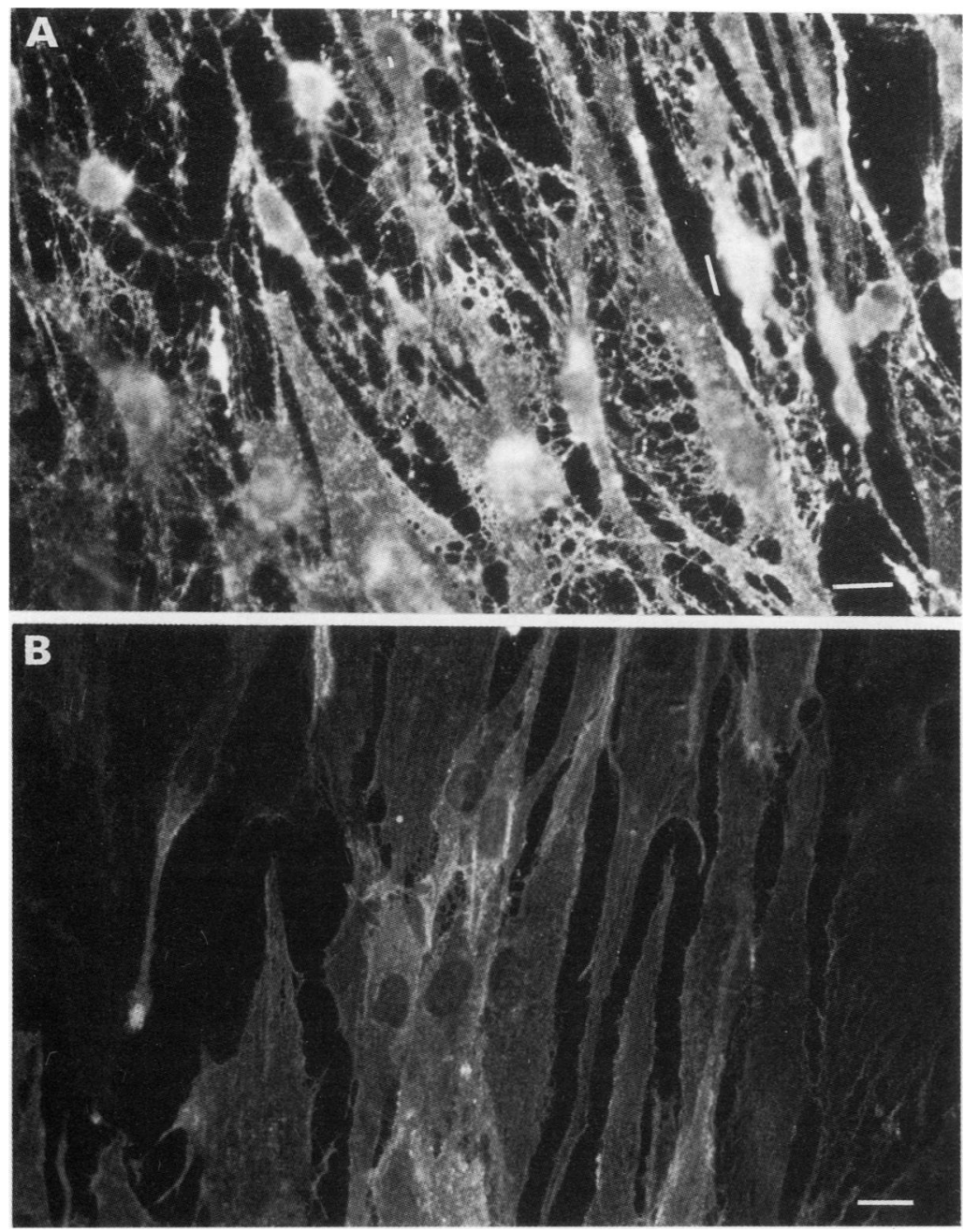

Figure 2 CD44 staining and normal $(A)$ and $R A(B)$ synovial fibroblasts. Normal cells show intense staining and many cytoplasmic processes. $R A$ cells, in comparison, show reduced staining intensity and far fewer cytoplasmic processes. Bar $=10 \mu \mathrm{m}$.

In another study by Haynes et $a l^{22}$ purporting to show that CD44 expression was upregulated in rheumatoid compared with normal synovium, equivalent weights of homogenised tissue were subjected to Western blotting and probed for CD44 content. Given, however, that CD44 appears to be purely cell associated, such studies require control for differences in tissue cellularity. An increase in tissue cellularity may overwhelm a concomitant decrease in individual cellular expression, resulting in an overall increase in tissue total CD44 content.
Further investigation of CD44 in the present study was performed on pure populations of cultured synovial fibroblasts at early passage. Relevant to this study is the fact that, in vivo, rheumatoid synovial cells are exposed to interleukin- $1 \beta$, interleukin- 6 , and tumour necrosis factor $\alpha .^{33}$ These cytokines have been shown to modulate the expression of extracellular matrix ${ }^{34}$ and cell adhesion molecules ${ }^{35}$ and it should be noted that their lack in culture may influence CD44 expression.

Western blot analysis, normalised for cell protein, and immunofluorescent staining each suggested that there was a decrease in CD44 expression in cultured rheumatoid cells. Cell based ELISA also showed a reduction in CD44 expression per cell in RA compared with normal, but only when the concentration of FCS was decreased to $0.5 \%$. For synovial cells serum is not the physiological fluid which they encounter in the synovium and the difference in CD44 expression between normal and RA cells may be reduced in the presence of mitogenic factors in the greater concentrations of serum. Nevertheless, the difference in CD44 expression in the presence of $2 \%$ serum was still of sufficient magnitude to be detected by Western blot analysis and immunofluorescence. However, in the cell based ELISA, differences in cell size could be a confounding factor. We have shown that cultured RA synovial cells are larger than normal and this may partially mask a reduction in receptors per unit surface area when CD44 expression per cell is measured in the cell based ELISA.

Immunofluorescent staining of cultured synovial fibroblasts showed that normal cells have CD44-positive processes which are not present on rheumatoid cells, indicating an alteration in the cytoskeleton. It is known that CD44 interacts with the cytoskeleton. ${ }^{36} \mathrm{~A}$ study using a mouse macrophage model of inflammation ${ }^{37}$ found a difference in CD44 phosphorylation and cytoskeletal association between resident cells and those which had been elicited to migrate to a site of inflammation. An earlier report found that cytoskeletal elements in rheumatoid synovial lining cells differed from those in normal cells. ${ }^{38} \mathrm{We}$ have demonstrated a difference in cell shape and area between normal and RA cells and this supports the view that the cytoskeleton is altered in RA cells. We conclude that the role

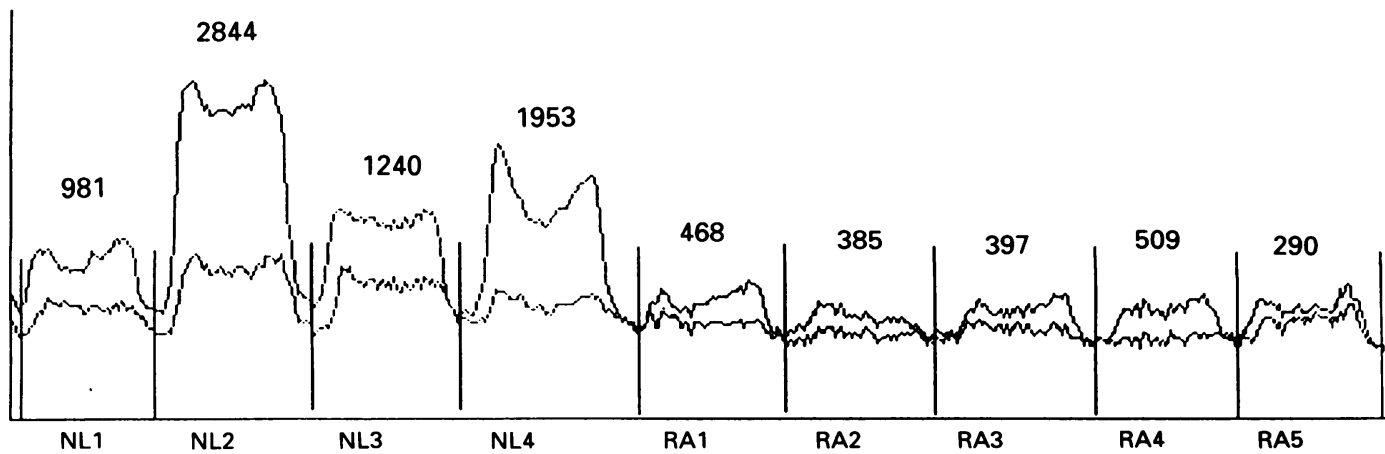

Figure 3 Western blot analysis of CD44 in cultured normal (NL) and RA synovial fibroblasts. The diagram shows the area under the densitometry curves (intensity of staining) for four normal and five $R A$ cell lines. The upper line is the curve obtained from the CD44 bands, the lower line is the reference curve obtained from an irrelevant area of the blot representing non-specific staining. The values represent the area between the curves for each cell line. 
of CD44 in RA may involve modulation of molecular associations of CD44 within the cell, together with a decrease in the total amount of cellular CD44.

We thank Dr M T Bayliss and Ray Hicks for valuable technical advice and Prof J Fabre and Dr M Fanger for supplying the monoclonal antibodies.

The authors acknowledge the support of the Arthritis and Rheumatism Council of Great Britain.

1 Aruffo A, Stamenkovich I, Melnick M, Underhill C B, Seed B. CD44 is the principal cell surface receptor for hyaluronate. Cell 1990; 61: 1303-13.

2 Picker L J, Naskache M, Butcher E C. Monoclonal antibodies to human lymphocyte homing receptors define a novel class of adhesion molecules on diverse cell types. a novel class of adhesion mol

3 Goldstein L A, Zhou D F H, Picker L J, et al. A human lymphocyte homing receptor, the Hermes antigen, is related to cartilage proteoglycan core and link proteins Cell 1989; 56: 1063-72.

4 Stamenkovic I, Amiot $M$, Pesando J M, Seed B. A lymphocyte molecule implicated in lymph node homin is a member of the cartilage link protein family. Cell 1989 56: $1057-62$.

5 Zimmermann D R, Ruoslahti E. Multiple domains of the large fibroblast proteoglycan, versican. $E M B O \mathcal{f} 1989 ; 8$ : 2975-81.

6 Peach R J, Hollenbaugh D, Stamenkovic I, Aruffo A Identification of hyaluronic binding sites in the extracellular domain of CD44 f Cell Biol 1993; 122: 257-64.

7 Jalkanen S, Jalkanen M. Lymphocyte CD44 binds the $\mathrm{COOH}$-terminal heparin-binding domain of fibronectin. f Cell Biol 1992; 116: 817-25.

8 Gallagher J T. The protein and proteoglycan guises of Hermes/CD44. Glycobiology 1992; 2: 93-4.

9 Springer T A. Adhesion receptors of the immune system Nature 1990; 346: 425-33.

10 Flanagan B F, Dalchau R, Allen A K, Daar A S, Fabre J W. Chemical composition and tissue distribution of the human CDw44 protein. Immunology 1989; 67: 167-75.

11 Jackson D G, Buckley J, Bell J I. Multiple variants of the human lymphocyte homing receptor CD44 generated by insertions at a single site in the extracellular domain. $\mathcal{f}$ Biol Chem 1992; 267: 4732-9.

12 Goldstein L A, Butcher E C. Identification of mRNA that encodes an alternative form of H-CAM (CD44) in lymphoid and nonlymphoid tissues. Immunogenetics 1990;

13 Arch R, Wirth K, Hofmann M, et al. Participation in normal immune responses of a metastasis-inducing splice variant of CD44. Science 1992; 257: 682-5.

14 Culty M, Nguyen H A, Underhill C B. The hyaluronan receptor (CD44) participates in the uptake and degradation of hyaluronan. 7 Cell Biol 1992; 116: 1055-62.

15 Thomas L, Byers R, Vink J, Stamenkovic I. CD44H regulates tumor cell migration on hyaluronate-coated substrate. f Cell Biol 1992; 118: 971-7.

16 Toole B P. Proteoglycans and hyaluronan in morphogenesis and differentiation. In: Hay E D, ed. Cell biology of the and differentiation. In: Hay E D, ed. Cell biology of the extracellutar

17 Weigel P H, Frost S J, LeBoeuf R D, McGary C T. The specific interaction between fibrin(ogen) and hyaluronan: possible consequences in haemostasis, inflammation, and wound healing. In: Evered D, Whelan J, eds. The biolog of hyaluronan. Ciba Foundation Symposium No. 143, 1989: 248-64.

18 Knudson W, Biswas C, Li X O, Nemec R E, Toole B P. The role and regulation of tumour-associated hyaluronan.
In: Evered D, Whelan J, eds. The biology of hyaluronan. Ciba Foundation Symposium No. 143, 1989: 150-69.

19 Balazs E A, Watson D, Duff I F, Roseman S. Hyaluronic acid in synovial fluid, I. Molecular parameters of hyaluronic acid in normal and arthritic human fluids. Arthritis Rheum 1967; 10: 357-76.

20 Castor C W. Abnormalities of connective tissue cells cultured from patients with rheumatoid arthritis, II Defective regulation of hyaluronate and collagen formation. $\mathcal{F}$ Lab Clin Med 1971; 77: 65-75.

21 Johnson B A, Haines G K, Harlow L A, Koch A E. Adhesion molecule expression in human synovial tissue. Arthritis Rheum 1993; 36: 137-46.

22 Haynes B F, Hale L P, Patton K L, Martin M E, McCallum R M. Measurement of an adhesion molecule as an indicator of inflammatory disease activity. Arthritis Rheum 1991; 34: 1434-43.

23 Letarte $M$. Human p85 glycoprotein bears three distinct epitopes defined by several monoclonal antibodies. Mol epitopes defined by several

24 Arnett E C, Edworthy S M, Bloch D A, et al. The American Rheumatism Association 1987 revised criteria for the classification of rheumatoid arthritis. Arthritis Rheum 1988; 31: 315-24

25 Yam L T, Li C Y, Crosby W H. Cytochemical identification of monocytes and granulocytes. Am f Clin Path 1971; 55: 283-90.

26 Chin J E, Winterrowd G E, Krzesicki R F, Sanders M E. Role of cytokines in inflammatory synovitis. Arthritis Rheum 1990; 33: 1776-86.

27 Henderson B, Edwards J C W, eds. Structure of the synovia lining. In: The synovial lining in health and disease. London: lining. In: The synovial lining in healt

28 Worrall J G, Bayliss M T, Edwards J C W. Morphological distribution of hyaluronan in normal and diseased distribution of hyaluronan in normal
synovium. $\mathcal{F}$ Rheumatol 1991; 18: 1466-72.

29 Pitsillides A A, Wilkinson L S, Mehdizadeh S, Bayliss M T, Edwards J C W. Uridine diphosphoglucose dehydrogenase activity in normal and rheumatoid synovium: the description of a specialized synovial lining cell. Int $\mathcal{f} E x$ Path 1993; 74: 27-34.

30 Worrall J G, Wilkinson L S, Bayliss M T. Edwards J C W. Zonal distribution of chondroitin-4-sulphate/dermatan sulphate and chondroitin-6-sulphate in normal and diseased human synovium. Ann Rheum Dis 1994; 53. 35-8.

31 Wilkinson L S, Edwards J C W, Poston R N, Haskard D $\mathrm{O}$. Expression of vascular cell adhesion molecule-1 in O. Expression of vascular cell adhesion molecule-1 in $82-8$.

32 Wolf J, Carsons S E. Distribution of type VI collagen expression in synovial tissue and cultured synoviocytes: relation to fibronectin expression. Ann Rheum Dis 1991 50: $493-6$.

33 Firestein G S, Alvaro-Garcia J M, Maki R. Quantitative analysis of cytokine gene expression in rheumatoid arthritis. F Immunol 1990; 144: 3347-53.

34 Sampson P M, Rochester C L, Freundlich B, Elias J A. Cytokine regulation of human lung fibroblast hyaluronan (hyaluronic acid) production. F Clin Invest 1992; 90: 1492-503.

35 Thiery J P, Boyer P. The junction between cytokines and cell adhesion. Curr Opin Cell Biol 1992; 4: 782-92.

36 Lacy B E, Underhill C B. The hyaluronan receptor is associated with actin filaments. F Cell Biol 1987; 105 1395-404.

37 Camp R L, Kraus T A, Puré E. Variations in the cytoskeleta interaction and posttranslational modification of the CD44 homing receptor in macrophages. $\mathcal{f}$ Cell Biol 1993 ; 115: 1283-92

38 Osung O A, Chandra $\mathrm{M}$, Holborow E J. Intermediate filaments in synovial lining cells in rheumatoid arthritis and other arthritides are of vimentin type. Ann Rheum Dis $1982 ; 41: 74-7$. 